\title{
LAPORAN AKTIVITAS PERAWATAN DIRI PASIEN HIPERTENSI DI KOTA BANDUNG
}

\author{
Eka Afrima Sari ${ }^{1^{*}}$, Sri Hartati Pratiwi ${ }^{2}$ \\ ${ }^{1,2}$ Fakultas Keperawatan Universitas Padjadjaran \\ Email Korespondensi: e.afrima@unpad.ac.id
}

Disubmit: 22 Januari 2022 Diterima: 24 Januari 2022 Diterbitkan: 01 Februari 2022

DOI: https://doi.org/10.33024/mnj.v5i2.5885

\section{ABSTRACT: REPORTS OF SELF-CARE ACTIVITIES OF PATIENT'S WITH HYPERTENSION IN BANDUNG CITY}

Introduction: Hypertension can be controlled by self-care. Self-care is an effort that can be done by both hypertensive patients and the patient's environment to prevent complications and improve the quality of life.

Purpose: This study aimed to identify reports of self-care activities by hypertensive patients.

Method: It used a descriptive quantitative approach_Participants consisted of 115 people with hypertension in primary health care, acquired through purposive sampling with inclusion criteria was aged $>18$ years old and in the treatment of hypertension. Reports of self-care activities were measured using $a$ Self-Reported Self-Care Activities on the Hypertension Self-Care Profile Instrument. Data were analyzed using frequency distribution.

Results: The results showed that as many as $52 \%$ of patients also measure blood pressure besides time to control in primary health care but do not record blood pressure readings regularly (87.83\%), as many as $59.13 \%$ of patients measure weight regularly but do not record weight readings regularly (96.52\%), patient's do not keep a food diary (99.13\%), the patient's do not use any mobile apps to maintain a healthy lifestyle (86.96\%), and as many as $80.87 \%$ of patients were never reduced by their doctor's dose of medicine.

Conclusion: This condition shows that self-reported self-care activities are not optimal, so efforts are needed to improve self-care that involves not only patients but also families and health services.

Keywords: hypertension, self-reported, self-care activities

\section{INTISARI: LAPORAN AKTIVITAS PERAWATAN DIRI PASIEN HIPERTENSI DI KOTA BANDUNG}

Latar Belakang: Hipertensi dapat dikendalikan dengan perawatan diri. Perawatan diri pasien hipertensi merupakan upaya yang dapat dilakukan baik oleh pasien hipertensi maupun lingkungan pasien untuk mencegah terjadinya komplikasi dan meningkatkan kualitas hidup pasien.

Tujuan: mengidentifikasi laporan aktifitas perawatan diri yang dilakukan oleh pasien hipertensi.

Metode Penelitian: Penelitian ini merupakan penelitian deskriptif pada 115 orang pasien hipertensi di Kota Bandung yang dipilih dengan teknik purposive 
sampling dengan kriteria inklusi usia > 18 tahun dan dalam pengobatan hipertensi. Laporan aktifitas perawatan diri dilihat berdasarkan instrumen SelfReported Self-Care Actvities pada Hypertension Self-Care Profile Instrument. Data dianalisis menggunakan distribusi frekuensi.

Hasil: Didapatkan sebanyak 52\% pasien memeriksakan tekanan darah selain pada jadwal kontrol di puskesmas namun tidak mencatat hasil pengukuran tekanan darah secara teratur $(87,83 \%)$, sebanyak $59,13 \%$ pasien menimbang berat badan secara teratur namun tidak mencatat hasil pengukuran berat badan secara teratur $(96,52 \%)$, sebanyak $99,13 \%$ pasien tidak menyimpan buku harian yang berisi makanan yang dikonsumsi, sebanyak $86,96 \%$ pasien tidak menggunakan aplikasi kesehatan pada handphone untuk menjaga gaya hidup sehat, dan sebanyak $80,87 \%$ pasien tidak pernah dikurangi dosis obatnya oleh dokter.

Simpulan: Hal tesebut menunjukkan bahwa perawatan diri yang dilaporkan oleh pasien hipertensi masih belum optimal, sehingga diperlukan adanya upaya untuk meningkatkan perawatan diri tersebut yang melibatkan tidak hanya pasien hipertensi, namun juga keluarga dan pelayanan kesehatan.

Kata kunci: Hipertensi, Laporan, Perawatan Diri

\section{PENDAHULUAN}

Hipertensi merupakan penyebab utama kematian di dunia (Hartzell, Avis, Lozano, \& Feig, 2016; Kementerian Kesehatan Republik Indonesia [Kemenkes RI], 2014). Indonesia mengalami peningkatan prevalensi hipertensi dari 25,8\% (tahun 2013) menjadi 34,1 $\%$ (tahun 2018) dan prevelensi hipertensi di Jawa Barat meningkat dari 30,1\% (tahun 2013) menjadi 38,5\% (tahun 2018) (Riset Kesehatan Dasar [Riskesdas], 2018). Hipertensi berada pada urutan ke empat $(7,11 \%)$ penyakit terbanyak di puskesmas Kota Bandung pada tahun 2014 (Profil Kesehatan Kota Bandung 2014, 2015).

Hipertensi dapat dikendalikan untuk mencegah terjadinya komplikasi, salah satunya dengan perawatan diri hipertensi. Peningkatan perawatan diri dapat menurunkan angka kematian yang berkaitan dengan hipertensi (Bilal, Haseeb, Lashkerwala, et al, 2016) serta menurunkan risiko penyakit kardiovakular (Verdecchia, Angeli, Gentile, Mazzota, \& Reboldi, 2011). Perawatan diri merupakan kemampuan individu, keluarga, dan masyarakat untuk berpartisipasi dalam promosi dan perlindungan kesehatan, pencegahan penyakit, dan penanganan penyakit serta kecacatan, baik dengan atau tanpa dukungan dari layanan kesehatan (Webber et al, 2013).

Tujuan dari perawatan diri pada pasien hipertensi adalah mencegah kekambuhan penyakit, mengurangi dampak dari komplikasi, meningkatkan kualitas hidup, meningkatkan derajat kesehatan, menurunkan intensitas rawat inap, dan menurunkan angka kematian (Agustina, 2017). Hasil penelitian menunjukkan sebanyak $50 \%$ pasien hipertensi yang tidak melakukan perawatan diri akan mengalami rawat inap (Navidian et al, 2015). Perawatan diri pasien hipertensi merupakan upaya yang dapat dilakukan baik oleh pasien hipertensi maupun lingkungan hidup disekitar pasien untuk mencegah terjadinya komplikasi dan meningkatkan kualitas hidup. Sehingga komplikasi maupun kematian akibat hipertensi dapat dicegah dan Jika sudah terjadi komplikasi dapat mengurangi dampak dari komplikasi tersebut. 
Tujuan dari penelitian ini adalah mengidentifikasi laporan aktifitas perawatan diri yang dilakukan oleh pasien hipertensi. Sehingga dengan diketahuinya aktifitas perawatan diri yang telah dilakukan pasien hipertensi ini, diharapkan menjadi bahan evaluasi bagi perawat guna meningkatkan pelaksanaan perawatan mandiri pasien.

\section{METODA PENELITIAN}

Penelitian ini merupakan penelitian deskriptif kuantitatif yang dilakukan pada 115 orang pasien hipertensi di Kota Bandung yang dipilih dengan teknik purposive sampling. Adapun kriteria inklusi yang digunakan pada penelitian ini adalah pasien hipertensi yang berusia > 18 tahun dan dalam pengobatan hipertensi.

Laporan aktifitas perawatan diri dilihat berdasarkan SelfReported Self-Care Actvities pada Hypertension Self-Care Profile Instrument (Han, Lee, CommodoreMensah, \& Kim, 2014 dalam (Ngoh, Lim, Koh, Tan, 2017). Pertanyaan pada instumen terdiri dari tujuh item pertanyaan mengenai pemeriksaan dan pencatatan pengukuran tekanan darah, pencatatan makanan yang dikonsumsi, penimbangan dan pencatatan hasil penimbangan berat badan, penggunaan aplikasi kesehata, dan pengurangan dosis obat oleh dokter. Instrumen telah dilakukan translasi dan uji konten oleh tiga orang yang berpengalaman dalam bidang self-care dan hipertensi. Hasil uji konten didapatkan beberapa penyesuaian pertanyaan sesuai dengan kondisi di Indonesia, khususnya pada pertanyaan nomor 1 terdapat perubahan yang sebelumnya berisi "Apakah Anda mengukur tekanan darah di rumah" menjadi "Apakah Anda memeriksakan tekanan darah selain pada jadwal kontrol di puskesmas?" dan pertanyaaan nomor 6 yang sebelumnya berisi "Apakah Anda menggunakan mobile apps untuk memonitor kesehatan atau kondisi medis?" menjadi "Apakah Anda menggunakan aplikasi kesehatan pada handphone untuk menjaga gaya hidup sehat?".

Data dianalisis menggunakan distribusi frekuensi. Penelitian ini telah mendapatkan persetujuan etik dari Komite Etik Penelitian Universitas Padjadjaran dengan nomor surat 671/UN6.KEP/EC/2018.

\section{HASIL PENELITIAN}

Karakteristik responden dilihat dari jenis kelamin, usia, lama menderita hipertensi, pendidikan, penyakit lain yang dimiliki, dan derajat hipertensi. Hal ini dapat dilihat pada tabel 1 dibawah ini.

Tabel 1. Distribusi Frekuensi Karakteristik Responden $(n=115)$

Karakteristik

Jenis Kelamin

Perempuan

Laki-laki

Usia

35-44 tahun

45-54 tahun

55-64 tahun

$\geq 65$ tahun

Lama Menderita Hipertensi
Frekuensi Persentase

(\%)

(f)

79.1

24

20.9

12

10.4

24

20.9

40

34.8

39

33.9 


\begin{tabular}{|c|c|c|c|}
\hline \multicolumn{2}{|l|}{ Karakteristik } & \multirow{2}{*}{$\begin{array}{c}\begin{array}{c}\text { Frekuensi } \\
\text { (f) }\end{array} \\
33\end{array}$} & \multirow{2}{*}{$\begin{array}{c}\text { Persentase } \\
\text { (\%) } \\
28.7\end{array}$} \\
\hline$\leq 1$ tahun & & & \\
\hline 2-5 tahun & & 50 & 43.5 \\
\hline 6-10 tahun & & 14 & 12.2 \\
\hline 11-20 tahun & & 13 & 12.3 \\
\hline$>20$ tahun & & 5 & 4.3 \\
\hline \multicolumn{4}{|l|}{ Pendidikan } \\
\hline SD & & 31 & 27.0 \\
\hline SMP & & 27 & 23.5 \\
\hline SMA & & 41 & 35.7 \\
\hline Universitas & & 16 & 13.9 \\
\hline \multicolumn{4}{|l|}{ Penyakit Lain } \\
\hline Hanya hipertensi & & 71 & 61,7 \\
\hline Diabetes melitus & & 11 & 9.6 \\
\hline Hiperkolesterol & & 13 & 11.3 \\
\hline Penyakit jantung & & 2 & 1.7 \\
\hline $\begin{array}{l}\text { Diabetes melitus } \\
\text { jantung }\end{array}$ & dan & 1 & 0.9 \\
\hline $\begin{array}{l}\text { Diabetes melitus } \\
\text { hiperkolesterol }\end{array}$ & dan & 1 & 0.9 \\
\hline Lain-lain & & 16 & 13.9 \\
\hline \multicolumn{4}{|l|}{ Tekanan Darah } \\
\hline Normal & & 2 & 1.7 \\
\hline Elevated & & 8 & 7.0 \\
\hline Hipertensi derajat 1 & & 9 & 7.8 \\
\hline Hipertensi derajat 2 & & 96 & 83.5 \\
\hline
\end{tabular}

Berdasarkan tabel 1, karakteristik pasien hipertensi yaitu berjenis kelamin perempuan (79.1\%), berusia $\geq 55$ tahun $(68.7 \%)$, dengan lama menderita hipertensi $\geq$ 2 tahun $(71.3 \%)$, berpendidikan SMA (35.7\%), memiliki penyakit selain hipertensi (38.3\%), dan hipertensi derajat II (83.5\%).

Laporan mengenai aktifitas perawatan diri pada pasien hipertensi, dapat dilihat pada tabel 2 dibawah ini.

Tabel 2. Laporan Aktifitas Perawatan Diri Pasien Hipertensi

\begin{tabular}{lcc}
\hline \multicolumn{1}{c}{ Pertanyaan } & $\begin{array}{c}\text { Ya } \\
\mathbf{f ( \% )}\end{array}$ & $\begin{array}{c}\text { Tidak } \\
\mathbf{f}(\%)\end{array}$ \\
\hline $\begin{array}{l}\text { Apakah Anda memeriksakan tekanan darah } \\
\text { selain pada jadwal kontrol di puskesmas? }\end{array}$ & $52 \%$ & $48 \%$ \\
$\begin{array}{l}\text { Apakah Anda mencatat hasil pengukuran } \\
\text { tekanan darah secara teratur? }\end{array}$ & $12,17 \%$ & $87,83 \%$ \\
$\begin{array}{l}\text { Apakah Anda menyimpan buku harian yang } \\
\text { berisi makanan yang dikonsumsi? }\end{array}$ & $0,87 \%$ & $99,13 \%$ \\
$\begin{array}{l}\text { Apakah Anda menimbang berat badan secara } \\
\text { teratur? }\end{array}$ & $59,13 \%$ & $40,87 \%$ \\
$\begin{array}{l}\text { Apakah Anda mencatat hasil pengukuran berat } \\
\text { badan secara teratur? }\end{array}$ & $3,48 \%$ & $96,52 \%$ \\
$\begin{array}{l}\text { Apakah Anda menggunakan aplikasi kesehatan } \\
\text { pada handphone untuk menjaga gaya hidup } \\
\text { sehat? }\end{array}$ & $13,04 \%$ & $86,96 \%$ \\
\end{tabular}




\begin{tabular}{lcc}
\hline \multicolumn{1}{c}{ Pertanyaan } & Ya & Tidak \\
& $\mathbf{f ( \% )}$ & $\mathbf{f ( \% )}$ \\
\hline $\begin{array}{l}\text { Apakah dokter pernah mengurangi dosis obat } \\
\text { hipertensi Anda? }\end{array}$ & $19,13 \%$ & $80,87 \%$ \\
\hline
\end{tabular}

Berdasarkan tabel 2, didapatkan sebanyak $52 \%$ pasien memeriksakan tekanan darah selain pada jadwal kontrol di puskesmas namun tidak mencatat hasil pengukuran tekanan darah secara teratur $(87,83 \%)$, sebanyak $59,13 \%$ pasien menimbang berat badan secara teratur namun tidak mencatat hasil pengukuran berat badan secara teratur $(96,52 \%)$, sebanyak 99,13\% pasien tidak menyimpan buku harian yang berisi makanan yang dikonsumsi, sebanyak $86,96 \%$ pasien tidak menggunakan aplikasi kesehatan pada handphone untuk menjaga gaya hidup sehat, dan sebanyak $80,87 \%$ pasien tidak pernah dikurangi dosis obatnya oleh dokter.

\section{PEMBAHASAN \\ Karakteristik Pasien}

Sebanyak 79,1\% pasien hipertensi adalah perempuan. Risiko penyakit kardiovaskular pada perempuan lebih rendah daripada laki-laki, namun perempuan akan mengalami peningkatan risiko setelah menopause (Lima et al, 2013). Hal ini terlihat pada usia pasien dengan hipertensi yang sebagian besar berusia $\geq 55$ tahun $(68,7 \%)$, dimana pada usia tersebut sudah terjadi menopause. Hal ini juga terlihat pada tekanan darah pasien hipertensi yang berada pada hipertensi derajat $2 \quad(83,5 \%)$, tingginya tekanan darah ini salah satunya dapat disebabkan oleh faktor usia sebagian besar responden yang memasuki masa menopause ( $\geq$ 55 tahun). Pada usia tersebut, terjadi penurunan hormon estrogen yang menyebabkan disfungsi endotel dan/atau vaskular melalui penurunan penyesuaian arteri besar serta terjadinya peningkatan viskositas darah yang dapat meningkatkan tekanan darah (Son et al, 2015).

Sebanyak 50,5\% tingkat pendidikan pasien adalah SD dan SMP. Hasil Riskesdas (2018) menunjukkan bahwa tingkat pendidikan yang rendah memiliki kecenderungan penyakit hipertensi yang tinggi. Sejalan dengan penelitian Anggara \& Prayitno (2013) menunjukkan bahwa terdapat hubungan yang signifikan antara tingkat pendidikan dengan kejadian hipertensi. Dimana tingkat pendidikan akan memengaruhi gaya hidup pasien yang berisiko terhadap kejadian hipertensi.

Sebanyak 38,3\% pasien memiliki penyakit penyerta selain hipertensi seperti diabetes mellitus, hiperkolesterol, dan penyakit jantung. Dengan adanya penyakit penyerta ini dapat memicu terjadinya komplikasi hipertensi dan memperberat kondisi hipertensi pada pasien.

Berdasarkan

lamanya menderita hipertensi, didapatkan bahawa pasien telah menderita hipertensi $\geq 2$ tahun (72,3\%), dengan rata-rata selama 8 tahun. Pasien terlama yang menderita hipertensi yaitu lebih 20 tahun. Lamanya pasien menderita hipertensi dapat berdampak pada kepatuhan pasien dalam menjalani perawatan diri hipertensi. Sejalan dengan penelitian yang dilakukan oleh Puspita (2016) menunjukkan bahwa kepatuhan dalam berobat berhubungan dengan lamanya menderita hipertensi.

Laporan Aktifitas Perawatan Diri 
Perawatan diri hipertensi mencakup kepatuhan pengobatan serta perubahan gaya hidup seperti tidak merokok, menjaga berat badan, diet rendah garam dan rendah lemak, aktifitas fisik, tidak konsumsi alkohol, monitoring tekanan darah sendiri, kunjungan ke dokter secara reguler, dan pengurangan stres (Han, 2014). Pada penelitian ini, laporan aktifitas perawatan diri pasien HT mencakup: pengukuran tekanan darah selain jadwal kontrol di puskesmas, mencatat hasil pengukuran tekanan darah secara teratur, menyimpan buku harian yang berisi makanan yang dikonsumsi, mengukur berat badan secara teratur, mencatat hasil pengukuran berat badan secara teratur, menggunakan aplikasi kesehatan pada mobile phone untuk memonitor kesehatan, dan pengurangan dosis obat oleh dokter. Laporan aktifitas perawatan mandiri pasien didapatkan bahwa sebagian besar pasien (52\%) pasien memeriksakan tekanan darah selain pada jadwal kontrol di puskesmas, namun hanya $12,17 \%$ yang mendokumentasikan hasil pengukurannya secara teratur. Sebagian besar pasien (59,13\%) menimbang berat badan secara teratur, namun hanya 3,48\% yang mendokumentasi hasil pengukurannya secara teratur. Menurut Ngoh (2017), skor HTN SCPMn (Hypertension Self Care Profile Mandarin Version) pada pasien yang mencatat hasil tekanan darah dan berat badan, lebih tinggi secara signifikan dibandingkan mereka yang tidak mendokumentasikan. Pemantauan mandiri tekanan darah di rumah secara rutin merupakan indikator yang baik dari perawatan diri, hal ini berdasarkan adanya korelasi yang tinggi antara selfreported measure dan skor HTN SCP$\mathrm{Mn}$. Pada penelitian ini dapat dilihat bahwa sebagian besar pasien berada pada hipertensi derajat dua. Hal ini salah satunya bisa disebabkan oleh masih ada sebagian besar pasien yang tidak memeriksakan tekanan darahnya selain pada jadwal di puskesmas dan tidak menimbang berat badannya secara teratur. Penelitian yang dilakukan oleh Anggara \& Prayitno (2013) dan Sulastri, Elmatris, \& Ramadhani (2012), menunjukkan bahwa terdapat hubungan antara indeks massa tubuh dengan hipertensi.

Laporan perawatan diri pasien HT seperti mencatat makanan yang dikonsumsi pada buku harian (food diary), penggunaan aplikasi kesehatan pada mobile phone, dan pengurangan dosis obat oleh dokter, hampir seluruh responden melaporkan tidak melakukannya. Sedikitnya responden yang melaporkan pengurangan dosis obat oleh dokter, sejalan dengan hasil pengukuran TD responden yang hampir seluruhnya $(83,5 \%)$ berada pada kategori HT derajat 2 . Sedikitnya responden yang menggunakan aplikasi mobile phone untuk memonitor kesehatannya, bisa dipengaruhi oleh usia responden yang sebagian besar $>55$ tahun dan tingkat pendidikan responden yang sebagian besar SD dan SMP. Dimana tingkat pendidikan akan memengaruhi gaya hidup pasien yang berisiko terhadap kejadian hipertensi. Kurangnya jumlah responden yang menyimpan buku harian berisi makanan yang dikonsumsi setiap harinya, dapat dipengaruhi oleh beberapa kondisi seperti usia dan lama responden menderita HT. Dimana lama menderita hipertensi ini juga berdampak pada kepatuhan dalam pelaksanaan pengobatan.

\section{SIMPULAN DAN SARAN}

Perawatan diri yang dilaporkan oleh pasien hipertensi masih belum optimal pada hampir semua aspek 
perawatan mandiri hipertensi, sehingga diperlukan adanya upaya untuk meningkatkan perawatan diri

\section{DAFTAR PUSTAKA}

Anggara, F.H.D., Prayitno, N. (2013).

Faktor-Faktor yang

Berhubungan dengan

Tekanan Darah di Puskesmas Telaga Murni Cikarang Barat Tahun 2012. Jurnal Ilmiah Kesehatan, 5(1).

Bilal, M., Haseeb, A., Lashkerwala, S.S., Zahid, I., Siddiq, K., Saad, M., Dar, M.I., Arshad, M.M., Shahnawaz, W., Ahmed, B., \& Yaqub, A. (2016). Knowledge, Awareness and Self-Care Practices of Hypertension among Cardiac Hypertensive Patients. Global Journal of Health Science, 8(2).

Han, Lee, Commodore-Mensah, Kim. (2014). Development and Validation of the Hypertension Self-Care Profile: A Practical tool to Measure Hypertension SelfCare Profile. $J$ Cardiovascular Nurs: 29(3).

Hartzell, K., Avis, K., Lozano, D., \& Feig, D. (2016). Obstructive sleep apnea and periodic limb movement disorder in a population of children with hypertension and/or nocturnal non dipping blood pressures. Journal of the American Society of Hypertension, 10(2), 101 107. https://doi.org/10.1016 /j.jash.2015.11.010

Kemenkes RI. (2014). Pusdatin Hipertensi. Infodatin, (Hipertensi), $1-$ 7. https://doi.org/10.1177/1 09019817400200403

Lima, R., Wofford, M., Reckelhoff, J.F. (2013). Hypertension in Postmenopausal tersebut yang melibatkan tidak hanya pasien hipertensi, namun juga keluarga dan pelayanan kesehatan.

Women. Curr Hypertens Rep, 14 (3).

Ma, Y.-Q., Mei, W.-H., Yin, P., Yang, X.-H., Rastegar, S. K., \& Yan, J.-D. (2013). Prevalence of hypertension in Chinese cities: a meta-analysis of published studies. Plos One, 8(3), e58302. https://doi.org/10.1371/jou rnal.pone.0058302

Navidian, A., Yaghoubinia, F., Ganjali, A., \& Khoshsimaee, S. (2015). The Effect of SelfCare Education on the Awareness, Attitude, and Adherence to Self-Care Behaviors in Hospitalized Patients Due to Heart Failure with and without Depression, 1-14.

doi.org/10.1371/journal.pon e. 0130973

Ngoh, Lim, Koh, Tan. (2017).Testretest reliability of the Mandarin versions of the Hypertension Self-Care Profile instrument. Medicine, 96:45(e8568).

Riskesdas. (2018). Riset Kesehatan Dasar 2018-Laporan Nasional 2018. Badan Penelitian dan Pengembangan Kesehatan, Departemen Kesehatan RI.

Puspita, E. (2016). Faktor-faktor yang berhubungan dengan Kepatuhan Pendeita Hipertensi dalam Menjalani Pengobatan (Studi Kasus di Puskesmas Gunungpati Kota Semarang). Unnes. Skripsi.

Seow, Yusoff, Koh, and Tan. (2018). What Is The Test-Retest Reliability of Malay Version of Hypertension Self-Care Profile Self Efficacy Assessment Tool? A Validation 
Study in Primary Care. BMJ Open.

Son, M., Lim, NK., Lim, JY. et al. (2015). The difference in blood pressure between early and late menopausal transitions was significant in healthy Korean women. BMC Women's

Health 15, 64. https://doi.or g/10.1186/s12905-015-0219$\underline{9}$

Sulastri, D., Elmatris, Ramadhani, R. (2012). Hubungan Obesitas dengan Kejadian Hipertensi pada Masyarakat Etnik Minangkabau di Kota Padang.
Majalah Kedokteran Andalas, 36 (2), Juli-Desember, 2012.

Verdecchia P, Angeli F, Gentile G, Mazzotta G, Reboldi G. (2011). Telmisartan for the reduction of cardiovascular morbidity and mortality. Expert Rev Clin Pharmacol, 4:51-

61. http://dx.doi.org/10.158 6/ecp.10.141

Webber D, Guo Z, Mann S. (2013). Self-Care in health: we can define it but should we also measure it. Self Care, 4(5):101-5. 